\title{
Evaluation of benzene exposure in adults and urinary s-phenylmercapturic acid in children living in Adelaide, South Australia
}

\author{
${ }^{1 *}$ A. R. Bahrami and ${ }^{2} J$. W. Edwards \\ ${ }^{1}$ Department of Occupational Health, Hamadan University of Medical Science, Hamadan, Iran \\ ${ }^{2}$ Department of Environmental Health, School of Medicine, Flinders University, Adelaide, Australia
}

Received 13January 2006;

revised 7 March 2006;

accepted 15 March 2006;

available online 20 April 2006

\begin{abstract}
Benzene Exposure was evaluated in adults and children living in Adelaide, South Australia by measuring benzene and urinary s-phenylmercapturic acid (SPMA). To determine of benzene exposure in each subject the personal passive samplers was used and samples were analyzed by gas chromatography system equipped to flame ionization detector. The level of SPMA was determined by competitive enzymelinked immunosorbent assay (ELISA) in children. The mean concentration of benzene in Summer and Winter were $1.62 \pm 1.43$ and $1.36 \pm 0.87 \mathrm{ppb}$ respectively. There was a significant difference between exposure to benzene for subjects with less and more than 6 hours activity over days of week $(\mathrm{p}<0.05)$. The mean urinary concentrations levels of SPMA adjusted to creatinene for children that living less and more than 200 meters distance from main road were 1.56 and $4.67 \mu \mathrm{mol} / \mathrm{mol}$ creatinene, respectively and the significant difference was seen in two groups $(\mathrm{p}<0.005)$. Data shows, that SPMA can be utilized as a biomarker for exposure to benzene in children. Exposure to benzene is more for children that living near to main road compare to other children. Adults have more activity in out side of home has more exposure to benzene than other people.
\end{abstract}

Key words: Benzene, s-phenylmercapturic acid (SPMA), trans, trans-muconic acid (TTMA), Biological monitoring, children

*Corresponding Author, E-mail:Bahrami@umsha.ac.ir

\section{INTRODUCTION}

Benzene, a component of petrol, is known carcinogen. A link between benzene exposure and leukemia has been established in some studies (Synder, 2000 and Guenel $e t$ al., 2002). The major sources of benzene in ambient air of urban area are motor vehicle exhaust and evaporation loss during handling, distribution and storage of petrol (Leung and Harrison, 1998). Biological monitoring of exposure to benzene includes measurement of benzene or its metabolite in blood, urine and exhale air (Weisel et al., 1996; Ong et al., 1996). Measurement of metabolite in urine prefer to analysis of benzene at blood because collection of urine is painless, easy to obtain, low in cost and easily performed even at subjects are far away from laboratory. An alternative approach involves measurement of the metabolites of benzene in urine including phenol, trans, trans-muconic acid (TTMA) and s-phenylmercapturic acid (SPMA) (ACGIH, 2005; Inoue et al. 2000; Boogaard et al., 1996). TTMA and SPMA were proposed to replace phenol in biological monitoring of benzene (Boogaard et al., 1996; ACGIH, 2005) Benzene in the human system is subsequently oxidized to benzene oxide and in turn conjugated with glutathione to form SPMA that is excreted in the urine (15). SPMA derives solely from benzene metabolism and is a sensitive and specific biomarker of exposed benzene in low level (Van Sitter et al., 1993, Ghittori et al., 1996). American Conference of Governmental Industrial Hygienists (ACGIH) introduce s-phenylmercapturic acid as biological exposure indices for benzene exposure (ACGIH, 2005). Most of studies have measured benzene in ambient air with passive or active sampler in some stations in streets. These studies have been performed at near retail petroleum outlets and in residential streets but few study was carried out concern to exposure to benzene based on people activity. Some studies also reports cancer in children living near to street and stay at traffic road(Duarte-Davidson, 2001 and Pearson, 2000) but researches concern to measurement of benzene metabolite in urine of children is very low (Amodio, 2001). The objective of this study is to evaluate atmospheric benzene exposure in adults by personal air sampling and determination of urinary SPMA of children group living near to the main road and comparison of results to children living far from the road. This research was done from 2001 to 2002 at South Australia. 


\section{MATERIALS AND METHODS}

Measurement of benzene exposure

43 adults living in Adelaide were selected to obtain air samples. A questionnaire that has some question about outside and inside activities of each subject over 24 hours in a week was used and completed by each subject. The samples of air were collected in both summer and winter seasons for subjects living in metropolitan Adelaide, using passive sampler tubes based on method T0-15 of United States Environmental Protection Agency (USEPA, 1997). Subjects were aged 22 to 66 years. Samples were collected from each subject daily for one week in each season. Samples tubes were desorbed thermally and transfer to a gas chromatography (PerkinElmer ATD 400) system with SGE BP20 capillary column and a flame ionization detector. Benzene concentrations were corrected for exposure period, using the equivalent air flow rate and have been expressed as parts per billion in air (ppb).

\section{Analysis of urinary SPMA in children}

Ninety seven urine samples were selected with simple random sampling from a 1300 preschool children in four areas of Metropolitan Adelaide. All children subjects were preschools, aged 4-5 years. There was a questionnaire, about the possible risk factors for benzene exposure. This questionnaire was completed by children parents. Sterile urine containers together with an information sheet and consent forms were distributed to parents via the kindergartens and childcare centers in each of the selected area. All children had no specific exposure to benzene other than that present in the general environment. The analysis of urine samples in this study was performed in January and February 2003. Urinary samples were acidified as soon as possible after collection and stored at $-20^{\circ} \mathrm{C}$ until dispatch for analysis. A method that recently developed based on competitive enzyme linked immunosorbent assay (ELISA) was used. This method specific for PMA and validated by correlation with GC/MS data (Aston et al., 2002). For analysis of samples, the frozen urine samples were kept at ambient temperature for $30 \mathrm{~min}$ and then centrifuged at $1500 \mathrm{rpm}$ for $5 \mathrm{~min}$. Ten micro liter of standards urine, and samples were added to a microtitre plate which had been coated with a PMA-boving serum albumin conjugate. After addition $100 \mu \mathrm{L}$ of an anti-PMA polyelonal antiserum, the plates were incubated for 1 hour at room temperature. The micro plate was washed with a solution of phosphate buffer salin containing
Tween-20 (0.05\%), the bound PMA fraction was incubated for a further hour with an alkaline phosphatelinked anti-sheep antibody $(100 \mu \mathrm{L})$. After another wash cycle and the addition of enzyme substrate solution (pni-trophenyl phosphate), the absorbance of the product was monitored at $405 \mathrm{~nm}$ using a microplate reader. The absorbance of standard solutions which inversely related to PMA concentration, were plotted as a function of the logarithm of PMA dose. The urinary creatinine was measured by Jaffe kinetic method without deproteinization on a Boehringer Mannheim Hitachi 917 automatic analyser and were reported following adjustment for creatinine concentration (measured as $\mathrm{mmol} / \mathrm{mol}$ creatinine to correct for urine dilution effects). Data analysis was performed with SPSS statistical software for windows. Comparison between the SPMA mean values (creatinine adjusted) was carried out with Mannt-whitnegtes test and for benzene concentration was obtained by the student's t-test. Linear regression analysis was used to describe the correlation between distance from road and SPMA in urine.

\section{RESULTS}

The mean value of benzene concentration for all subjects were $1.5 \pm 1.80$. The mean concentration of benzene measured in population are shown in Table 1, the results indicate a significant difference for subjects with outside activities less than 6 hours and more than 6 hours activities $(p<0.005)$. The mean concentration of benzene for people that have more than 6 hours activity in winter is more than summer. There was not significant different between benzene concentration in summer compare to winter. There was a significant difference between benzene concentrations for subjects their home was less than $200 \mathrm{~m}$ to road compare to subjects more than $200 \mathrm{~m}$ far from road in winter $(\mathrm{p}<0.05)$ but no significant difference was found between two groups in summer. Table 2 shows the levels of the urinary PMA measured in this study with and without adjustment for creatinine. There was a significant difference between PMA level for children living less than $200 \mathrm{~m}$ from road compare to children living more than $200 \mathrm{~m}$ $(\mathrm{p}<0.05)$. The urinary SPMA levels, expressed nmol/ $\mathrm{L}$, were two-half fold higher in children near road compare to children far from road and when adjusted for creatinine, still there is significant difference between two groups. No significant difference was seen between the Urinary PMA for children their parents smoker with non-smokers. 
Table 1: Concentrations of benzene measured in exhaled air of each subject in Adelaide

\begin{tabular}{lllllll}
\hline \multicolumn{1}{c}{ Concentration } & N. & $\begin{array}{l}\text { Summer } \\
\text { Mean }\end{array}$ & S.D. & N. & $\begin{array}{l}\text { Winter } \\
\text { Mean }\end{array}$ & S.D. \\
\hline $\begin{array}{l}\text { Total concentration of benzene } \\
\text { subjects less than 6 hours out }\end{array}$ & 43 & 1.62 & 1.43 & 43 & 1.36 & 0.87 \\
$\begin{array}{l}\text { side activity } \\
\text { subjects more than 6 hours out }\end{array}$ & 19 & 0.85 & 0.55 & 19 & 1.16 & 0.65 \\
$\begin{array}{l}\text { side activity } \\
\begin{array}{l}\text { Living more than } 200 \mathrm{~m} \text { far } \\
\text { from road }\end{array}\end{array}$ & 24 & 1.71 & 1.56 & 24 & 2.43 & 1.39 \\
$\begin{array}{l}\text { Living less than } 200 \mathrm{~m} \text { far } \\
\text { from road }\end{array}$ & 23 & 1.55 & 1.16 & 21 & 0.97 & 0.60 \\
\hline
\end{tabular}

Table 2: Urinary S-PMA results determined in children living in South Australia

\begin{tabular}{lccccc}
\multicolumn{1}{c}{ Parameter } & N. & $\begin{array}{c}\text { Mean } \\
(\mathrm{nmol} / \mathrm{L})\end{array}$ & S.D. & $\begin{array}{c}\text { Mean } \\
(\mu \mathrm{mol} / \mathrm{mol} \\
\text { creatinene) }\end{array}$ & S.D. \\
\hline $\begin{array}{l}\text { Total SPMA } \\
\text { House locality: }\end{array}$ & 97 & 23.95 & 28.00 & 2.97 & 3.77 \\
$\begin{array}{l}\text { More than 200 m from road } \\
\text { Less than 200 m from road }\end{array}$ & 45 & 12.78 & 9.94 & 1.47 & 1.03 \\
Passive smoker: & 52 & 34.36 & 35.37 & 4.47 & 4.82 \\
No & & & & & \\
Yes & 17 & 21.39 & 20.56 & 2.44 & 2.56 \\
\hline
\end{tabular}

\section{DISCUSSION AND CONCLUSION}

The results of this study showed that, activities undertaken by each subject over of $24 \mathrm{~h}$ are importance factor in exposure of people to benzene. This study measured mean of benzene concentration in $24 \mathrm{~h}$ over weekly exposure, but most of studies in other countries have measured benzene in ambient air with active or passive samplers in special sites in street. The mean concentration of benzene in London, Hong Kong, Manila, Bangkok, Mexico city, Rome, Milan and Tehran were ranged from 4.00 to 39.90 ppb (Duarte-Davidson et al., 2001; Lee et al., 2002; Gee and Sollar, 1998; Brocco et al., 1997; Bahrami 2001; Fernando et al., 1999). If the results are compared with the above-mentioned results, the mean concentration of benzene in Adelaide $(1.50 \mathrm{ppb} \pm 1.80)$ was less than other studied locations that may concern to extension of the city in great area with range of 40 to $25 \mathrm{~km}$ and length of 90 to $50 \mathrm{~km}$ (UBD, 2003). Motor vehicles can be considered to the main sources of air pollution in the Adelaide metropolitan, in which, the total number of motor vehicles registered in South Australian have increased steadily since 1979 at an overall annual growth rate of 2.1 percent per year. In south Australia at 1995, there were 653 motor vehicles per 1000 persons, an increase of 2.4 percent from the 1993 motor vehicle census.
(Environment Protection Authority, 1998). The present study focuses on the accumulating of urinary SPMA in children using a newly developed, technically simple, based on competitive enzyme linked immunosorbent assay (ELISA) specific for SPMA. The comparison of quantitative results generated by ELISA and GC/MS was done by Astone et al., and indicate a correlation $(\mathrm{R}=0.92)$ (Aston et al., 2002). Data in this study demonstrated there are significant difference in urinary SPMA levels in children depending on distance of location from road. It may concern to pollution in road emitted by vehicle. The individual variable such as potential home benzene exposure to passive smocking, cooking and heating were not significant confounding factors in subjects living in south Australia. There was not any significant difference between measurement of urinary SPMA in winter and summer and also among four areas in Adelaide. It may concern to concentration of benzene in seasons and extension of Adelaide in a great area. No significant difference between children their parents were smoker with no-smoker. It may concern to strong interference of outside sources of pollution. This is the first study, which examined urinary SPMA levels of children in South Australia. Studies of urinary PMA levels in other countries is also rare. At the present time the measurement of urinary SPMA is 
the method most frequently used for the biological monitoring of workers who are exposed to benzene. Biological monitoring for benzene and metabolite for environmental exposure has not been used extensively. In study by Chio et al., (2000) measuring PMA in people living near petrochemical industrial areas in Korea the geometric mean and the maximum amount of data were 7.89 and $109.68 \mu \mathrm{g} / \mathrm{g}$ creatinine respectively. In another study at Koria (Fang et al., 2000) correlation coefficient for urinary PMA in children near to the petrochemical with benzene in ambient air was 0.90 . The urinary SPMA at the present study was less than study by Yoonho and others carried out in industrial area. It may concern to benzene concentration in air. PMA a more reliable biomarker than TTMA for monitoring benzene exposure (Boogaard, 1995). Some studies reported that TTMA is not a high sensitive biomarkers for exposure to benzene in low concentration because sorbic acid (common food preservative) converted to TTMA and is a positive interference (Giovanni et al., 2001; Barbiers et al., 2002). PMA also was recognized to be an appropriate biomarkers for monitoring of benzene because it is unique metabolite derived from benzene and has a longer half-life. (Boogaard and Sitter, 1995; Van Sittert et al., 1993). It is concluded that SPMA can be utilized as a biomarker for exposure to benzene in children. The children and adults that living near to main road have more exposure to benzene. Adults that more activity in outside of home has more exposure to benzene in ambient air compare to people stay at home. It is recommended that authorities decrease amount of benzene in petrol and develop an emission database transport and monitor benzene in main road.

\section{REFERENCES}

American Conference of Governmental Industrial Hygienists. (2003). Threshold limit values for chemical substances and physical agents and biological exposure Indices. ACGIH worldwide, cincinnati, ISBN 1-88241749-6.

Amodio, C. R., (2001). Evaluation of benzene exposure in children living in Campania (Italy) by urinary trans, trans-muconic acid assay. J. Toxicol. Environ. Health., Part A., 63, 79-87.

Aston, J. P., Ball, R. L., Pople, J. E., Jones, K. and Cocker, J., (2002). Development and validation of a competitive immunoassay for urinary S-phenylmercapturic acid and its application in benzene biological monitoring. Biomarkers, 7 (2), 103-112.

Bahrami, A. R., (2001). Distribution of volatile organic compounds in ambient air of Tehran. Arch. Environ. Health, 56 (4), 380-383.
Barbiers, A., Accorsi, A., Raffi, G. B., Nicoli, L., Violante, F. S., (2002). Lack of sensitivity of urinary trans, transmuconic acid in determining low level (ppb) benzene exposure in children. Arch. Environ. Health, 57 (3), 224-228.

Boogaard, P. J. and Sitter, N. J., (1995). Biological monitoring of exposure to benzene a comparison between S-phenylmercapturic acid, trans, trans-muconic acid, and phenol. Occup. Environ. Medicine, 52, 611-620.

Boogaard, P. J. and Sitter, N. J., (1996). Suitability of sphenyl mercapturic acid and trans-muconic acid as biomarkers for exposure to low concentration of benzene. Environ. Health Perespect., 104, 1151-1157.

Brocco, D., Fratarcangeli, R., Lepore, L., Petricca, M. and Venrrone, I., (1997). Determination of aromatic hydrocarbons in urban air of Rome. Atmos. Environ., 31, 551-566.

Chio, C., Dongchun, S., Seongeun, P., Yong, C. and Myungsoo, K., (2000). Biological Monitoring of benzene in residents living near petrochemical Industrial Area in Korea. J. Occup. Health, 42, 31-37.

Duarte-Davidson, R., Courage, C., Rushton, L. and Levy, L., (2001). Benzene in the environment: an assessment of the potential risks to the health of the population, Occup. Environ. Med., 58, 2-13.

Environment Protection Authority, (1998). State of the Environment Report for South Australia, Heritage and Aboriginal Affairs.

Fang, M. Z., Shin, M. K., Park, K. W., Kim, Y. S., Lee, J. W. and Cho, M. H., (2000). Analysis of urinary Sphenylmercapturic acid and trans, trans-muconic acid as exposure biomarkers of benzene in petrochemical and industrial areas of Korea. Scand J work Environ Health, 26, 62-66.

Fernando, M., Isabelle, R., Matiana, R., Steve, C., Kochy, F., David, A. and Mauricio, A. H., (1999). A survey of personal exposure to benzene in Mexico city. Arch. Environ. Health, 54, 359-363.

Gee, I. L. and Sollars. C. J., (1998). Ambient air levels of volatile organic compounds in latin American and Asian cities. Chemosphere, 36, 2497-2506.

Ghittori, S., Imbriani, M., Masetri, L., Capodaglio, F. and Cavalleri, A., (1999). Determination of S-phenylmercapturic acid in urine as an indicator of exposure to benzene. Toxicol. Letter., 108, 329-334.

Giovanni, S., Antonio, A., Anna, B., Giovanni, B. R. and Francesco, S. V., (2001). Failure of urinary trans, transMuconic acid as a biomarker for indoor environmental benzene exposure at ppb levels. J. Toxicol. Environ. Health, Part A, 63, 599-604.

Guenel, P., Imbernon, E., Chevalier, A., Crinquand, C. A. and Goldberg, M., (2002). Leukemia in relation to occupational exposures to benzene and other agents: a case-control study nested in a cohort of gas and electric utility workers. Am J Ind Med., 42 (2), 87-97.

Inoue, O., Kanno, E., Kakizaki, M., Watanabe, T., Higashikawa, K. and Ikeda, M., (2000). Urinary phenylmercapturic acid as a marker of occupational exposure to benzene, Ind. Health., 38, 195-204.

Lee, S. C., Chiu, M. Y., Ho, K. F., Zou, S. C. and Wang, X., (2002). Volatile organic compounds in urban atmosphere of Hong Kong. Chemosphere, 48, 375-382. 
Leung, P. L., and Harrison, R. M., (1998). Evaluation of personal exposure to monoaromatic hydrocarbons, Occup. Environ. Med., 55 (4), 249-257.

Ong, C. N., Kok, P. W., Ong, H. Y., Shi, C. Y., Lee, B. L., Phoon, W. H. and Tan, K. T., (1996). Biomarkers of exposure to low concentrations of benzene: a field assessment. Occup Environ Med., 53, 328-33.

Harris, Robert L., (2000). Patty’s Industrial Hygiene (5 ${ }^{\text {th }}$ Ed.), John Wiley \& Sons.

Pearson, R. L., Wachtel, H. and Ebi, K. L., (2000). Distanceweighted traffic density in proximity to a home is a risk factor for leukemia and other childhood cancers. J Air Waste Manag Assoc. 50, 175-80.

Synder, R., (2000). Overview of the toxicology of benzene. J. toxicol. Environ. Health A. 61, 339-46.

UBD, (2002). Street directory Adelaide, Universal Press PTY.
USEPA (1997). Compendium Method TO-15: Determination of volatile organic compounds (VOCs) in air collected center for Environmental Research, Information Office of Research and Development, EPA/625/R-96/010b, U.S.

Van, Sittert, N. J., Boogard, P. J. and Beulink, G. D., (1993). Application of the urinary S-phenylmercapturic acid test as a biomarker for low levels of exposure to benzene in industry. Br. J. Ind. Med., 50, 460-469.

Weisel, C., Yu, R., Roy, A., and Georgopoulos, P., (1996). Biomarkers of environmental benzene exposure. Environ Health Perspect., 104, 1141-1146.

Yardley-jones, A., Anderson, D. and Park, D. V., (1991). The toxicity of benzene and its metabolism and molecular pathology in human risk assessment. Br. J. Ind. Med., 48, 437-444.

\section{AUTHOR(S) BIOSKETCHES}

Bahrami, A. R., M.Sc., Ph.D., is a senior lecturer in the Department of Occupational Health, н а m adan universityofmedicalscience, нат adan, iran.e-mai : Bahrami@umsha.ac.ir

Edwards, J. W., Ph.D., is associate professor in Occupational and Environmental Health and supervise research students at Department of Environment Health, Flinders University, Adelaide, South Australia, 5001. E-mail: John.edwards@flinders.edu.au

This article should be referenced as follows:

Bahrami, A. R. and Edwards, J. W., (2006). Evaluation of benzene exposure in adults and urinary S-Phenylmercapturic acid in children living in Adelaide, South Australia. Int. J. Environ. Sci. Tech., 3 (2), 113-117. 